“( 2016 IEEE. Personal use of this material is permitted. Permission from IEEE must be obtained for all other uses, in any current or future media, including

reprinting/republishing this material for advertising or promotional purposes, creating new collective works, for resale or redistribution to servers or lists, or reuse of any copyrighted component of this work in other works." 


\title{
Identifying target for technology mergers and acquisitions using patent information and semantic analysis
}

\author{
Lu Huang ${ }^{1}$, Lining Shang ${ }^{1}$, Kangrui Wang ${ }^{1}$, Alan L. Porter ${ }^{2,3}$, Yi Zhang ${ }^{1,4}$
}

\begin{abstract}
Technology plays an increasingly important role in today’s enterprise competition. Technology mergers and acquisitions (Tech M\&A), as an effective way to acquire external technology resources rapidly, have attracted attentions from researchers for their potential realization of value through synergy. A big challenge is how to identify appropriate targets to support effective technology integration. In this study, we developed a model of target selection of Tech M\&A from the perspective of technology relatedness and R\&D capability. We presented the results to the Tech M\&A case in China's cloud computing industry.
\end{abstract}

\section{Introduction}

Rapid technological change and diverse customer needs make firms face increasing pressure of innovation. When enhancing the innovative capabilities, even the largest and most technologically self-sufficient firms do not always have the time to build their own new technologies from scratch. Getting external technology resources to enhance existing technology portfolios has been a preferred choice for firms.

Technology mergers and acquisitions (Tech M\&A), as an effective way to get external technology resources, has been a hot topic for innovation management(Sears and Hoetker, 2014; Lodh and Battaggion, 2014). Tech M\&A enables firms to get quick access to the research frontier in the field of competence (Yoon et al 2013), and facilitates firms to enter new technology areas with lower time cost and reduced R\&D failure risk(Hussinger, 2010). The main effect of Tech M\&A is to achieve technological synergy to enhance acquirer's innovative

\footnotetext{
${ }^{1}$ Lu Huang $(\square)$

e-mail: huagnlu628@163.com

${ }^{1}$ Beijing Institute of Technology, School of Management and Economics, Beijing P.R.China

${ }^{2}$ Georgia Institute of Technology, Technology Policy \& Assessment Ctr., School of Public Policy, Atlanta, GA - USA

${ }^{3}$ Search Technology, Inc., Norcross, GA - USA

${ }^{4}$ University of Technology Sydney, Centre for Quantum Computation \& Intelligent Systems, Sydney - Australia
} 
capability(Guardo et al,. 2015). The research on Tech M\&A can be divided into three stages:

In the first stage, scholars found that in some cases, firms could develop significantly fast after acquiring some small technology-based firms. Granstrand et. al (1982) strived to conclude key factors to Tech M\&A success based on 13 M\&A events in high tech industries.

In the second stage, researchers began to explore motivations of Tech M\&A and evaluate performance, especially from the perspective of finance. Scholars used multi-dimensional indexes and chose various time frames to evaluate acquisition performance(Loughran and Vijh, 1997; Kohers, N., \& Kohers, 2000).

Now, in the third stage, research on Tech M\&A tends to be diversified, including Tech M\&A integration, Tech M\&A mode, and Tech M\&A target selection. Paruchuri (2006) analyzed the relationship between the research personnel and innovation output during Tech M\&A integration. Tian and Xin (2011) identified attributes of target companies and proposed a theory to support the decision making of acquiring companies through four in-depth case studies conducted across three primary sectors in the medical technology industry. Lin(2012) tested an acquisition-learning-innovation framework and found that unrelated acquisitions also enhance exploration in an era of technology fermentation. Research at this stage mainly focuses on performance evaluation after Tech M\&A. Few studies have been conducted on target selection preacquisition.

The volume of Tech M\&A events has been steadily increasing in recent years. However, it is not easy to realize Tech M\&A successfully. The failure rate of Tech M\&A is pretty high -- between $70 \%$ and $90 \%$ (Christensen et al., 2011). Taking account of the $\$ 2$ trillion transactions of M\&A every year, the failures are extremely costly. Tech M\&A success or failure can be determined and influenced by many factors, e.g. strategic formulation, technology relatedness, and financial status. But the most fundamental step to increase the success of M\&A is to select the right target companies, which are well matched to the strategic purpose of a given M\&A action (Kengelbach and Roos, 2011).

Existing studies on identifying M\&A targets concentrate primarily on development or application of financial and managerial variables (i.e., firm size, cash flow, and debt-to-equity ratio), neglecting considering the technological perspective (Ragothaman et al., 2003; Ali-Yrkkö, et al., 2005).

Patents, as an important source for the management of technology both in industry and science, are useful sources for technology analysis. Traditional methods are mainly based on International Patent Classification (IPC) and citation without considering the text of patents, which constrains the analysis depth. Recently, the proliferation of patents worldwide has increased the demand for more-advanced quantitative patents analysis to support the experts' evaluation process for decision-making (Yoon and Kim 2012; Yoon et al 2013). In this paper, we introduce semantic analysis to devise a new framework to analyse technology relatedness, including technology similarity and technology complementarity of 
Tech M\&A. We apply our method to Huawei Technologies Co. Ltd (Huawei), a China's leading firm in the field of cloud computing, for Tech M\&A needs.

\section{Challenges and Methods}

Tech M\&A, by its very nature, is a method to get external technology resources. The primary factor in target selection of Tech M\&A is technical relatedness. However few methods have been proposed to analyse it. A big challenge that corporate managers and government policy makers are facing is how to confirm a methodological architecture to help them identify the appropriate target to support effective technology integration.

Our research is based on the following driving questions:

1. How do we use a quantitative method to measure technology relatedness?

2. What factors should be considered for effective technology integration based on the analysis of technology relatedness?

3. How to devise a comprehensive method from the perspective of technology relatedness and technology integration on post-acquisition stage?

In this study, we try to provide detailed guidance for identifying potential Tech M\&A targets from a technological perspective based on patent information. Patents have long been considered to be up-to-date and valuable information sources in technology, and careful analysis of patents could provide information of not only technological competitiveness, but also overall technological opportunity in the specific technology areas. Therefore, the technological capabilities of a corporation can be represented by its set of patents. 


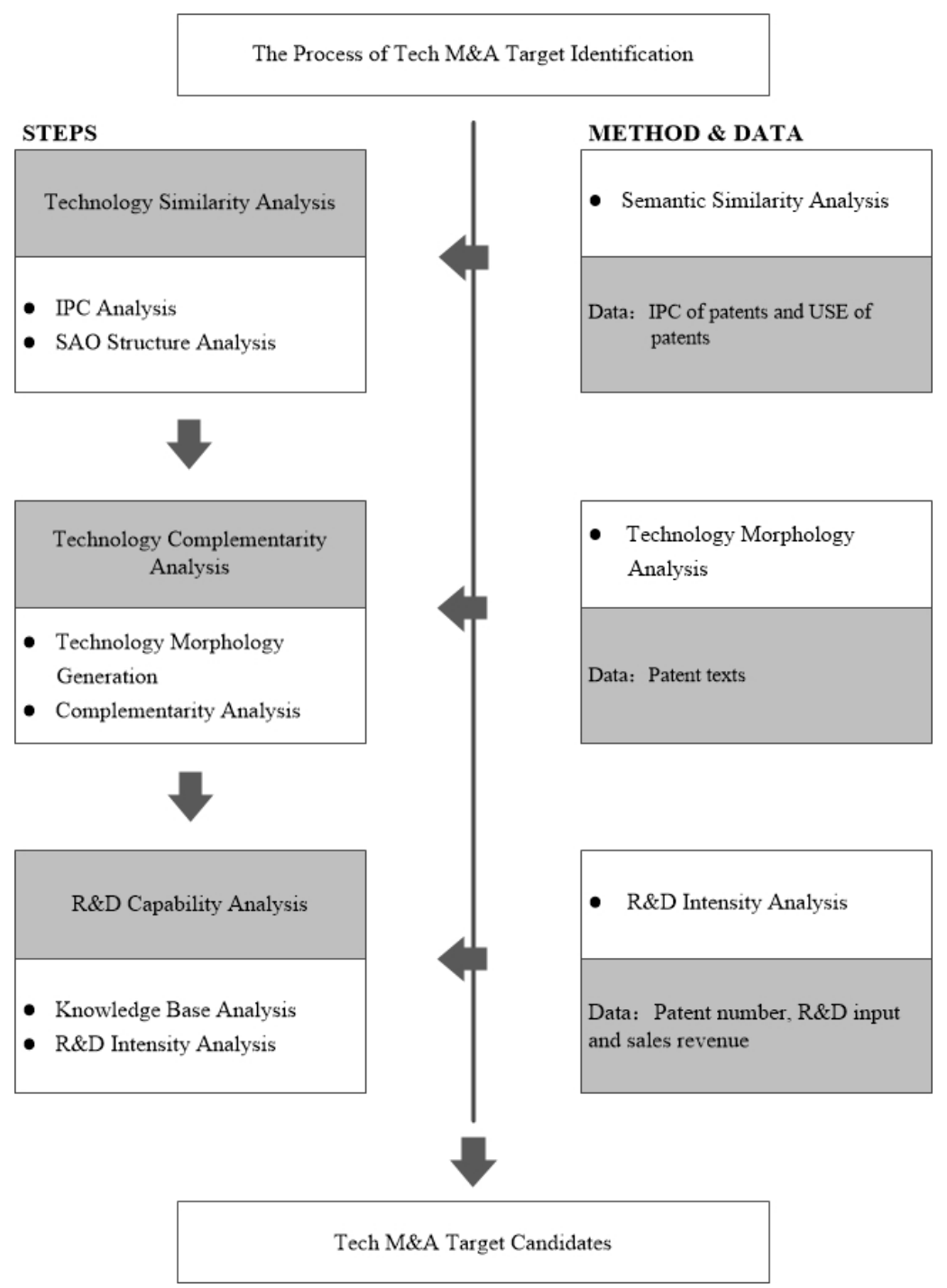

Fig. 1.Tech M\&A Target Identification Process

In this study, we divide the method of Tech M\&A target selection into three steps based on patent analysis. Figure 1 shows the process.

Step 1: Technology Similarity Analysis — The purpose of this step is to calculate the technology similarity between the acquirer and targets, and reduce the selection scope for step 2. First, IPC of each patent will be extracted and the degree of overlap will be regarded as the preliminary evaluation of consistency of technology area. Second, we measure technology similarity through Subject Action - Objective (SAO) analysis of the USE field in the abstract of patents after choosing the potential candidates of high consistency with the acquirer. 
Step 2: Technology Complementarity Analysis- - Technology morphology analysis is introduced to help the complementarity analysis. First, we extract keywords from patent texts and arrange them according to the related technology. Second, we calculate the complementarity of each technology combination with the help of expert experience.

Step 3: R\&D capability analysis — We use knowledge base and R\&D intensity as indicators to make further selection of potential targets after the first two steps.

For technology similarity analysis, we extract the IPCs of every patent and measure the consistency of technology area with the method of Makri (2010). After that, NLP tools are used to extract the SAO structures from the patents collected with the help of open API. In order to identify the semantic similarity of SAO structures, a semantic knowledge base, WordNet, is introduced to calculate the similarity between two words or phrases in the SAO structures.

For technology complementarity analysis, first, we extract the keywords from patents and map them into their associated morphology. Second, we evaluate the technology complementarity level with the help of experts, and calculate the technology complementarity finally.

For R\&D capability analysis, we emphasize the view of knowledge base and R\&D intensity of potential targets. Knowledge base of a firm is measured by the related number of patents, and R\&D intensity is measured by a firm's ratio of expenditures on R\&D to the firm's sales.

\section{Case Study}

\subsection{Patent Collection}

Rapid technology renewal keeps emerging technology a hotspot in Tech M\&A for years, and we chose a representative one -- cloud computing technology, focusing on opportunities within China. Patents for cloud computing were collected from the Derwent Innovations Index (DII), employing the search strategy by Owens (2012), from 2000 to 2012. We got 621 patents on cloud computing of China after data cleaning.

The patent database consisted of 621 DII patent abstract records chosen with the search strategy by Owens. Table 1 lists the top 10 assignees. According to technology development strategy and the layout of the cloud computing technology area, we chose Huawei Corp (Huawei) as an acquirer to search for Tech M\&A targets. Huawei is a global leading provider of Information Communication Technology solutions, and is also the most professional one-stop cloud service provider in China. Huawei has been expanding the layout of cloud computing since 2010, and in the year 2011, Huawei acquired Huasy Firm for 
5,300 million dollars to enhance the security of cloud platforms. Tech M\&A is regarded as an important way to achieve rapid development of related technologies on cloud computing for Huawei.

Table 1. Top 10 Assignees in cloud computing

\begin{tabular}{lll}
\hline Assignee Names & Patent Number & Percentage \\
\hline ZTE Corp & 52 & $8.4 \%$ \\
Microsoft Corp & 41 & $6.6 \%$ \\
Inspur electronic information co ltd & 33 & $5.3 \%$ \\
LI Z (Individual) & 24 & $3.9 \%$ \\
Huawei Crop & 23 & $3.7 \%$ \\
IBM Corp & 21 & $2.7 \%$ \\
Univ Qinghua & 19 & $2.1 \%$ \\
Hon Hai Precision Ind Co Ltd & 19 & $1.9 \%$ \\
Guangdong Electronics Ind Inst Co Ltd & 17 & $1.4 \%$ \\
Univ Beijing Aeronautics \& Astronautics & 15 & $1.4 \%$ \\
\hline
\end{tabular}

\subsection{Technology Similarity Analysis}

Literature on Tech M\&A suggested that the maximum benefits from an acquisition can be realized when technology portfolios of both firms are related (Hussinger, 2010; Gupta, 2013; Ahn et al., 2014). We applied Makri’s theory (Makri et al., 2010) to make a preliminary assessment of technology similarity between the Acquirer and the Target (A\&T) with the help of IPC analysis. IPC of patents shows the distribution of technology area. Technology similarity of firms with high consistency of technology distribution will probably be higher than the others'. The measure of technology similarity is described below. The Total Patent A\&T in the formula means the total number of patents of both the acquirer and the target.

$$
\text { Techno } \log y \text { Similarity }=\frac{\text { Overlap All Patent Class }}{\text { Total Patent } A \& T} \times \frac{\text { Total Acquirer Patent In Common Classes }}{\text { Total Acquirer Patent }} \text { (4.1) }
$$

We extracted IPC information from the patents collected to illustrate technology similarity. We refined the data first. Individual assignees and firms whose total number of cloud patents was fewer than 6 were excluded. Second, we defined the degree of "common classes." For example, there are three patents $\mathrm{P}_{1}$, $\mathrm{P}_{2}, \mathrm{P}_{3}$ with the IPC H04L29/08, H04L29/06, H04H60/72. $\mathrm{P}_{1}$ and $\mathrm{P}_{2}$ represent similarity because they are under the same subcategory H04L29, and the combination with $\mathrm{P}_{3}$ does not. In this way, we calculated the technology similarity between the acquirer and the potential target for each of the leading Chinese firms in the domain. The results are shown in Table 2. The left part of the table is the 
potential target list and the right part is the evaluation of technology area. We found that GCI SCI\&Technology Co Ltd (GCI), Shanghai Hechen Information Technology (Hechen), ZTE Corp (ZTE), and Shuguang Cloud Computing Technology Co (Shuguang) offer high consistency in technology area. The IPC distribution is densely located in H40L29 and G06F09.

\begin{tabular}{ll}
\multicolumn{2}{c}{ Table 2. Preliminary Technology Similarity Analysis } \\
\hline Potential Targets & Preliminary Technology Similarity Analysis \\
\hline GCI SCI\&Technology Co Ltd & 0.064 \\
Shanghai Hechen Information Technology & 0.061 \\
ZTE Corp & 0.058 \\
Shuguang Cloud Computing Technology Co & 0.053 \\
Inspur Electronic Information Co Ltd & 0.048 \\
Hon Hai Precision Ind Co Ltd & 0.036 \\
Microsoft Corp & 0.024 \\
IBM Corp & 0.014 \\
Beijing Z \& W Technology Consulting Co. & 0.011 \\
Ltd. & 0.009 \\
Yulong Computer Telecom Technology & 0.008 \\
Shenzhen Zidong Technology Co Ltd & \\
\hline
\end{tabular}

We further analyzed technology similarity from the perspective of SAO structure of patent text. The SAO structure can express the precise meaning and can thus represent technological key-concepts and key-findings in the patent. Moehrle et al. (2005) proposed a method of using patent-based inventor profiles to guide human resource decisions. Park et al. (2013) used semantic patent maps to identify technological competition trends for R\&D planning. We extracted the USE field from the abstract of patents and then transformed the content to SAO structures (Table 3). After filtering out some duplicated SAO structures using a set of stopwords (STOPWORDS, 2011), we got the data ready for semantic analysis.

Table 3 Sample of extracted SAO structure from patents

\begin{tabular}{|c|c|c|}
\hline $\mathbf{S}$ (Subject) & A (Action) & $\mathbf{O}$ (Object) \\
\hline Method & Execute & $\begin{array}{l}\text { Software application e.g. batch application and user- } \\
\text { interactive application, on a computer system, } \\
\text { according to a SLA }\end{array}$ \\
\hline $\begin{array}{l}\text { System for creating a } \\
\text { composite public cloud }\end{array}$ & Delivery & Hosted services \\
\hline Method & Schedule & Cloud computing open platform \\
\hline $\begin{array}{lr}\text { Virtualized } & \text { desktop } \\
\text { application } & \text { display } \\
\text { platform } & \end{array}$ & Used & Cooperative computing of an electric power system \\
\hline System & Control & Quantum microscopy instrument \\
\hline Issuing & Based & Cloud computing and data asynchronous transmission \\
\hline
\end{tabular}




\begin{tabular}{|c|c|c|}
\hline invoice & & technology \\
\hline Method & Protect & Data and privacy of user in cloud environment \\
\hline $\begin{array}{l}\text { Multi-tenant service } \\
\text { providers }\end{array}$ & Request & Dynamic platform reconfiguration \\
\hline $\begin{array}{l}\text { Distributed systems on } \\
\text { a set of computer } \\
\text { processors }\end{array}$ & Perform & Coordinated upgrades \\
\hline $\begin{array}{ll}\text { Experiment cloud } \\
\text { platform system }\end{array}$ & Manage & Computer calculation and software resources \\
\hline
\end{tabular}

WordNet-based semantic similarity between two SAO structures is computed by using the C\# library (Simpson and Dao, 2005). We set a threshold value as 0.7 to determine if the two SAO structures are the same according to semantic similarity calculation results and the advice of experts. If the result is more than s, the two structures can be considered the same. For any two SAO structures $\left(\mathrm{SAO}_{\mathrm{i}}\right.$ and $\mathrm{SAO}_{\mathrm{j}}$ ), we determined the Similarity (SIM) between them as:

$$
\operatorname{SIM}\left(S A O_{i}, S A O_{j}\right)=\left\{\begin{array}{l}
1, \text { if }\left(\text { Measure }\left(S A O_{i}, S A O_{j}\right)\right) \geq S \\
0, \text { otherwise }
\end{array}\right.
$$

The USE of a patent includes more than one SAO structure. We defined the semantic similarity between the patents as the basis of how many SAO structures the two patents share. Suppose that there are two patents $\mathrm{P}_{1}$ and $\mathrm{P}_{2}$, and we denote that $\operatorname{Num}_{\mathrm{SAO}}\left(\mathrm{P}_{1}\right)$ is the number of SAO structures in patent $\mathrm{P}_{1}, \operatorname{Num}_{\mathrm{SAO}}\left(\mathrm{P}_{2}\right)$ is the number of SAO structures in patent $\mathrm{P}_{2}$, and $\operatorname{Num}_{\mathrm{SAO}}\left(\mathrm{P}_{1}, \mathrm{P}_{2}\right)$ is the number of the semantically identical SAO structures shared by patents $\mathrm{P}_{1}$ and $\mathrm{P}_{2}$. The Patent Similarity (PSIM) can be described as:

$$
\operatorname{PSIM}\left(P_{1}, P_{2}\right)=\frac{2 \times \operatorname{Num}_{S A O}\left(P_{1}, P_{2}\right)}{\operatorname{Num}_{S A O}\left(P_{1}\right)+\operatorname{Num}_{S A O}\left(P_{2}\right)}
$$

After measuring the similarity between patents, we took the pairwise average similarity of patents owned by two different firms as the technology similarity. For any two firms $\left(\mathrm{F}_{1}, \mathrm{~F}_{2}\right)$, Firm Technology Similarity (FSIM) could be measured as:

$$
\operatorname{FSIM}\left(F_{1}, F_{2}\right)=\frac{\sum_{i=1}^{i=P N\left(F_{1}\right)}\left(\sum_{j=1}^{j=P N\left(F_{2}\right)} \operatorname{PSIM}\left(P_{i}, P_{j}\right)\right)}{P N\left(F_{1}\right) \times P N\left(F_{2}\right)}
$$


Here, $P N\left(F_{1}\right)$ and $P N\left(F_{2}\right)$ are the patents of the two firms $\left(F_{1}\right.$ and $\left.F_{2}\right)$ respectively, and the $\operatorname{PSIM}\left(\mathrm{P}_{\mathrm{i}}, \mathrm{P}_{\mathrm{j}}\right)$ means the patent similarity of the two firms. Figure 2 illustrates the degree of technology similarity between each other and the first column is the technology similarity with Huawei.

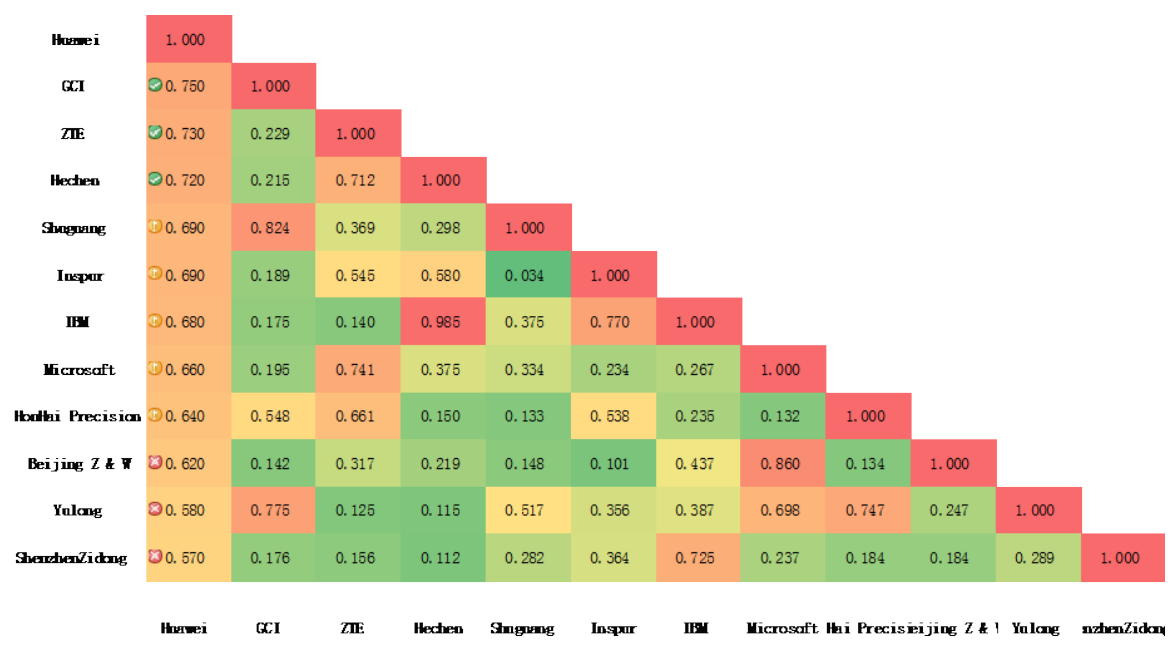

Fig 2 Degree of technology similarity between each other of the selected firms

We found that the top 3 firms with highest technology similarity with Huawei were GCI, ZTE, and Hechen. The result matched with the IPC analysis that technology similarity of firms with high consistency of technology distribution is higher. We chose the firms whose technology similarity with Huawei was not less than 0.7 for technology complementarity.

Table 4. Technology Similarity Evaluation of potential targets

\begin{tabular}{ll}
\hline Potential Targets & Technology Similarity \\
\hline GCI SCI\&Technology Co Ltd & 0.75 \\
ZTE Corp & 0.73 \\
Shanghai Hechen Information Technology & 0.72 \\
Shuguang Cloud Computing Technology Co & 0.69 \\
Inspur electronic information co ltd & 0.69 \\
IBM Corp & 0.68 \\
Microsoft Corp & 0.66 \\
Hon Hai Precision Ind Co Ltd & 0.64 \\
Beijing Z \& W Technology Consulting Co. Ltd. & 0.62 \\
Yulong Computer Telecom Technology & 0.58 \\
Shenzhen Zidong Technology Co Ltd & 0.57 \\
\hline
\end{tabular}




\subsection{Technology Complementarity Analysis}

Analysis of technology complementarity is based on the result of the technology similarity analysis. Technology complementarity is considered as an important driver of invention (Golombek and Hoel, 2004). Acquiring complementary technologies can promote exploratory learning within the organization, which may accelerate the process of innovation (Cassiman and Veugelers, 2006). Different from technology similarity, complementary technology contributes to post-merger invention performance by stimulating higher quality and more novel inventions (Miozzo et al., 2011). Sparse research has been conducted on the measurement of technology complementarity at the pre-acquisition stage. In this paper, we introduce morphology analysis for this. Technology Morphology Analysis was introduced to patent assessment by Yoon (2005) and now is widely used for technology opportunity analysis. Technology complementarity before Tech M\&A can be evaluated by analysing different technology morphological combinations with the help of expert experience.

First, we converted the patents into structured data using keyword vectors according to their frequency of occurrence and with reference to technology dictionaries. Second, we set words associated with a specific technology and appearing frequently as keywords. Then, we mapped the patent keywords into their associated morphology and got Table 5, which shows the main technologies, subdivision technologies, and the corresponding keywords of cloud computing from the patents.

Table 5. Technology Morphology of cloud computing

\begin{tabular}{|c|c|c|}
\hline \multicolumn{2}{|c|}{ Main Technology composition } & Sample Keywords \\
\hline \multirow{2}{*}{ Display Technology } & Based on plug-in & Flash, Silverlight, JavaFX \\
\hline & Based on browser & HTML5, Ajax, CSS3 \\
\hline \multirow{3}{*}{ Multi-tenancy } & Shared nothing & Separate database, Separate schema \\
\hline & Shared hardware & $\begin{array}{l}\text { Shared Database, separated data storage, } \\
\text { Additional storage subsystems }\end{array}$ \\
\hline & Shared everything & $\begin{array}{l}\text { Shared schema, network monitoring, Shared } \\
\text { schema }\end{array}$ \\
\hline \multirow{3}{*}{ Virtualization } & Platform virtualization & $\begin{array}{l}\text { Virtual Machine Monitor, Hypervisor, Host } \\
\text { OS }\end{array}$ \\
\hline & Resource virtualization & Load balancing, Monitoring Resources \\
\hline & Application virtualization & $\begin{array}{l}\text { Virtual terminal, remote Access, application } \\
\text { Access }\end{array}$ \\
\hline \multirow{3}{*}{ Security } & Application security & $\begin{array}{l}\text { Anti-virus services, Network security } \\
\text { monitoring, DDoS attack warning }\end{array}$ \\
\hline & Platform security & $\begin{array}{l}\text { Access control management, Security API, } \\
\text { Network security }\end{array}$ \\
\hline & Infrastructure security & Secure Hypervisor, Full Disk Encryption, \\
\hline
\end{tabular}




\begin{tabular}{|c|c|}
\hline & Secure Virtual Machine \\
\hline Distributed Storage & $\begin{array}{l}\text { Horizontal scalability, area network storage, } \\
\text { secret sharing }\end{array}$ \\
\hline
\end{tabular}

After that, we generated a table of subdivision technology complementarity according to experts' assessment for complementarity between Huawei and the potential targets. If the firms had related patents, we added a group of lines to indicate that they had related technologies. The groups of vertical lines and horizontal lines reflected the technology distribution of Huawei and the target respectively. The depth of background colour of each cell showed the complementarity level, which was divided into 3 layers and the white background meant the two technologies had no complementarity. The crossing lines with red background meant the two firms had complementary technologies. The table was symmetrical, so we took the lower triangular region for analysis. We set the degree of complementarity to three levels marked by the depth of colour and the three levels were set as 1, 2 and 3 for calculation. To measure the technology complementarity, we just needed to take the cells with crossing lines and background into consideration. Again we supposed there were two firms $F_{1}$ and $F_{2}$. We denoted the related patent number of $F_{1}$ and $F_{2}$ in the ith cell with crossing lines and red background as $\mathrm{F}_{1} \mathrm{PN}(\mathrm{i})$ and $\mathrm{F}_{2} \mathrm{PN}(\mathrm{i})$. The complementarity formula between the two firms is below:

$$
\text { Complementarity }=\sum_{\in \mathcal{W}}\left(F_{1} P N(i) \times F_{2} P N(i) \times \text { complementarity level }\right)
$$

where the D means the technology areas in which the technologies of the two firms are complementary. After calculating the complementarity of all the potential targets with the acquirer, we normalize the result by calculating the percentage of each complementarity result in the sum of all the complementarity results.

We took GCI (GCI SCI \& Technology Co Ltd) as an example. The technology complementarity of the two firms is shown in Table 6. The two firms had complementary technologies in the area of display technology area and security technology area, of which the cells appear with crossing lines and red background. For GCI, 1 patent was on display technology of based on plug-in, 2 patents were based on browsers, and 2 patents on application virtualization. For Huawei, 3 patents were on platform security. Using (5), we calculated the technology complementarity as 39 . We could compute the technology complementarity for the remaining firms in the same way. We then carried out a normalization process. Technology complementarity of other potential targets is listed in Table 7. ZTE had the highest complementarity with Huawei, the second being GCI, and the third being Hechen. 
Table 6. Technology Complementarity of Huawei and GCI

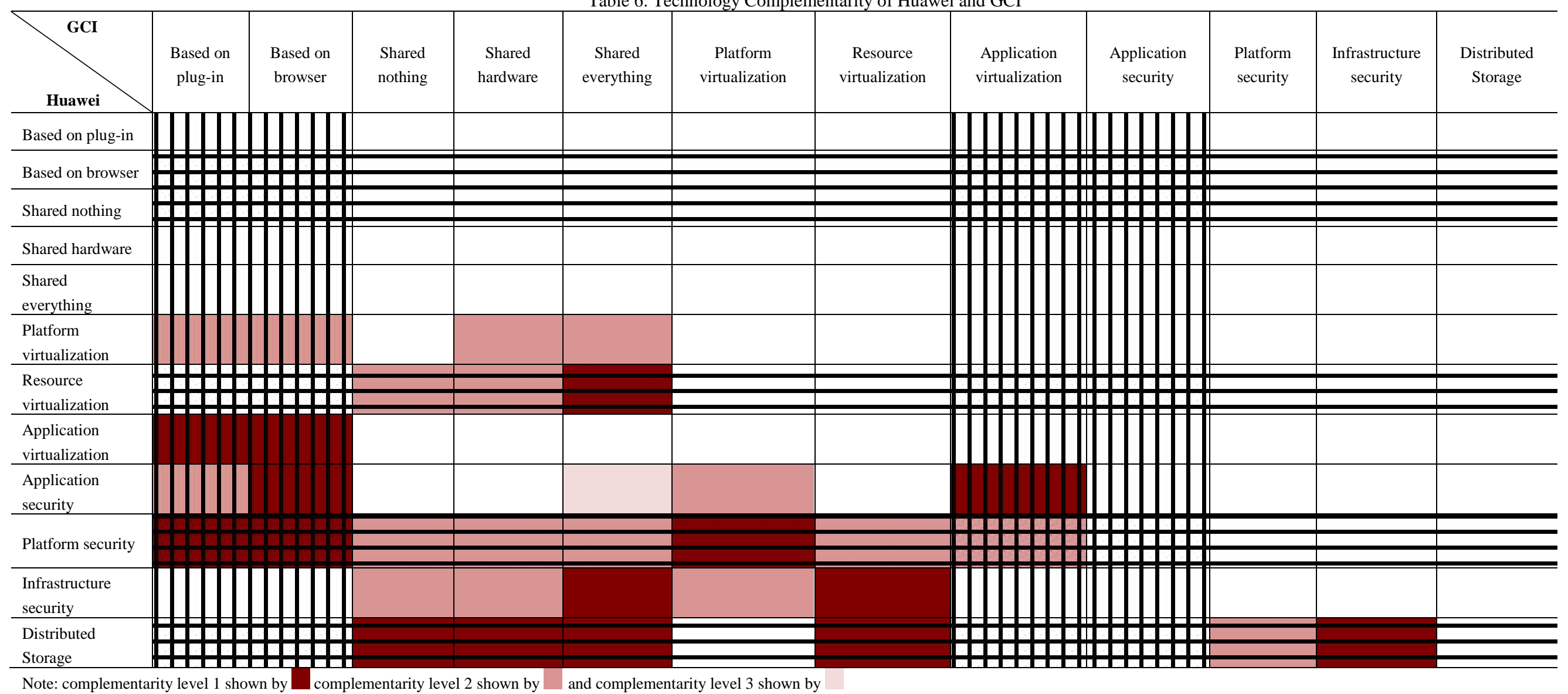

Note: complementarity level 1 shown by complementarity level 2 shown by and complementarity level 3 shown by

\begin{tabular}{ll}
\multicolumn{2}{c}{ Table 7. Technology Complementarity Evaluation of potential targets } \\
\hline Potential Targets & Technology Complementarity \\
\hline ZTE Corp & 0.56 \\
GCI SCI\&Technology Co Ltd & 0.23 \\
Shanghai Hechen Information Technology & 0.21 \\
\hline
\end{tabular}




\subsection{R\&D capability analysis}

Wu and Reuer (2014) indicated that R\&D capability is an important factor of technology integration and innovation after Tech M\&A. Acquiring firms with high R\&D capability will promote technology integration and technology synergy creation after Tech M\&A(Benitez and Ray, 2012). In this study, we used the absolute size of the knowledge base measured by the number of related patents and $R \& D$ intensity to evaluate the $R \& D$ capability of candidate acquisitions. $R \& D$ intensity was defined as the ratio of expenditures by a firm on R\&D to the firm's sales. We used the average of three years' ratio. All of the three firms could be target candidates for Huawei from the perspective of Tech M\&A, and ZTE was the most appropriate target. Considering the scales of the three firms, if Huawei hoped to become the leading firm through Tech M\&A, ZTE Corp could be the better target; if Huawei hoped to enhance subdivision technologies in cloud computing, Shanghai Hechen and GCI would be the better choice.

Table 8. Appropriate target candidates of Tech M\&A for Huawei

\begin{tabular}{lll}
\hline Potential Targets & Knowledge Base & R\&D Intensity \\
\hline ZTE Corp & 52 & 0.12 \\
Shanghai Hechen Information Technology & 13 & 0.06 \\
GCI SCI\&Technology Co Ltd & 10 & 0.05 \\
\hline
\end{tabular}

\section{Conclusions}

This paper presented a framework to identify and evaluate companies from the technological perspective to support M\&A target selection decision-making. The paper took technology similarity, technology complementarity, and R\&D intensity as main indicators to evaluate potential targets. We introduced patent text analysis to generate a more comprehensive method for technology relatedness evaluation.

First, technology similarity was preliminarily evaluated according to patent IPCs. Further analysis was conducted using SAO-based semantic similarity analysis based on patent text. The approach enables one to extract the technological key-concepts and key-findings in patents and can complement the IPC-based analysis. Firms with high technology similarity with the acquirer can be selected.

Second, technology morphology analysis was introduced to analyze the technology complementarity between the targets and the acquirer. Keywords from patent text were mapped into their associated morphology. Technology complementarity level was set by the experts to all the possible technology 
combinations. The technology complementarity could be computed according to the patent distribution and the corresponding technology complementarity level. Thus, firms were further selected.

Third, this paper used R\&D capability, including the absolute size of knowledge base and R\&D intensity, to help choose the targets for an acquirer. We verified the usability and practicality of the method by applying it to patents related to cloud computing technologies, and selected Huawei Technologies Co. Ltd. as an example to assess Tech M\&A in the cloud computing technology area.

During the whole analysis process, we kept in contact with department of cloud computing of Huawei. Huawei showed interest in our research results, especially the measurement of the technology similarity and technology complementarity. Huawei extended the further requests for the research including further technology similarity and complementarity analyses and the analysis of technology development trends of cloud computing, to support the firm's present work.

However, there are a few limitations in the study. Some doubts remain regarding the reliability of patent data. Sometimes patent data cannot reflect the core technology of a firm because an emerging technology is not yet allowed for patenting. The analysis based on patents does not take the tacit knowledge into account. Another limitation is to what extent the framework can be applicable to other industries. Firms in some kinds of industries may not have many patents, though they have complex knowledge. Other indicators, such as the stage of technology development and the range of multiple sector interests of the players, should be considered in further study.

Acknowledgments This research was undertaken at Georgia Tech and Beijing Institute of Technology drawing on support from the National Science Foundation (NSF) through the Science of Science Policy Program - "Measuring and Tracking Research Knowledge Integration" (Georgia Tech; Award No. 0830207); and the National Science Foundation of China Young Funds (Beijing Institute of Technology; Award No. 71103015). The findings and observations contained in this paper are those of the authors and do not reflect the views of the NSF and NSFC.

\section{References}

1. Sears J, Hoetker G. Technological overlap, technological capabilities, and resource recombination in technological acquisitions[J]. Strategic Management Journal, 2014, 35(1): 48-67.

2. Lodh S, Battaggion M R. Technological breadth and depth of knowledge in innovation: the role of mergers and acquisitions in biotech[J]. Industrial and Corporate Change, 2014: dtu013.

3. Park, H., Yoon, J., \& Kim, K. (2013). Identification and evaluation of corporations for merger and acquisition strategies using patent information and text mining. Scientometrics, 97(3), 883-909. 
4. Hussinger, K. (2010). On the importance of technology relatedness: SMEs versus large acquisition targets. Technovation, 30(1), 57-64.

5. Di Guardo, C., Harrigan, K. R., \& Marku, E. (2015). Quantity at Expense of Quality? Measuring the Effects of Technological M\&A on Innovation and Firm Performance. Measuring the Effects of Technological M\&A on Innovation and Firm Performance.

6. Loughran, T., \& Vijh, A. M. (1997). Do long-term shareholders benefit from corporate acquisitions?. Journal of finance, 1765-1790.

7. Kohers, N., \& Kohers, T. (2000). The value creation potential of high-tech mergers. Financial Analysts Journal, 56(3), 40-51.

8. Paruchuri, S., Nerkar, A., \& Hambrick, D. C. (2006). Acquisition integration and productivity losses in the technical core: Disruption of inventors in acquired companies. Organization Science, 17(5), 545-562.

9. Wei, T., \& Tian, X. (2011). How to Select Target Firms in M\&As? Evidence from the Medical Technology Industry. IJEI: International Journal of Engineering and Industries, 2(2), 8-26.

10. Lin, L. H. (2012). Innovation performance of Taiwanese information firms: An acquisitionlearning-innovation framework. Total Quality Management \& Business Excellence, 23(910), 1135-1151.

11. Christensen, C. M., Alton, R., Rising, C., \& Waldeck, A. (2011). The big idea: the new M\&A playbook. Harvard Business Review, 89(3), 48-57.

12. Kengelbach, J., \& Roos, A. W. (2011). Riding the Next Wave in M\&A: Where are the Opportunities to Create Value?. Boston Consulting Group, Incorporated.

13. Ragothaman, S., Naik, B., \& Ramakrishnan, K. (2003). Predicting corporate acquisitions: An application of uncertain reasoning using rule induction. Information Systems Frontiers, 5(4), 401-412.

14. Ali-Yrkkö, J., Hyytinen, A., \& Pajarinen, M. (2005). Does patenting increase the probability of being acquired? Evidence from cross-border and domestic acquisitions. Applied Financial Economics, 15(14), 1007-1017.

15. H. Park, J. Yoon and K. Kim, "Identification and evaluation of corporations for merger and acquisition strategies using patent information and text mining," Scientometrics, vol. 97, pp. 883-909, 2013.

16. Makri, M., Hitt, M. A., \& Lane, P. J. (2010). Complementary technologies, knowledge relatedness, and invention outcomes in high technology mergers and acquisitions. Strategic Management Journal, 31(6), 602-628.

17. Owens, T., \& Logue, F. (2012). Cloud Computing The Irish Perspective.

18. Gupta, P. K. (2013). MERGERS AND ACQUISITIONS (M\&A): THE STRATEGIC CONCEPTS FOR THE NUPTIALS OF CORPORATE SECTOR. Innovative Journal of Business and Management, 1(4).

19. Ahn, J. M., Minshall, T., \& Mortara, L. (2014). Open innovation: an approach for enhancing performance in innovative SMEs. Available at SSRN 2431205.

20. M. Moehrle and A. Geritz, "Developing acquisition strategies based on patent maps," 13th Iamot, Washington, DC, 2004.

21. Stop words project, "stop-words", Retrieved 1/21/15 Word Wide Web, https://code.google.com/p/stop-words/

22. Tory Simpson and Thanh Dao, "WordNet-based semactic similarity measurement", Retrieved 1/12/15 Word Wide Web

23. R. Golombek and M. Hoel, "Unilateral emission reductions and cross-country technology spillovers," Advances in Economic Analysis \& Policy, vol. 3, 2004.

24. B. Cassiman and R. Veugelers, "In search of complementarity in innovation strategy: Internal R\&D and external knowledge acquisition," Management science, vol. 52, pp. 68-82, 2006.

25. M. Miozzo, L. DiVito and P. Desyllas, "Cross-border acquisitions of science-based firms: Their effect on innovation in the acquired firm and the local science and technology system," DRUID Conference16 June, vol. 18, 2011. 
26. Yoon, B., \& Park, Y. (2005). A systematic approach for identifying technology opportunities: Keyword-based morphology analysis. Technological Forecasting and Social Change, 72(2), 145-160.

27. J. Benitez-Amado and G. Ray, "Introducing IT-enabled Business Flexibility and IT Integration in the Acquirer's M\&A Performance Equation," 2012.

28. Wu, C. W., \& Reuer, J. J. (2014, January). Effects of R\&D Investments and Signals on International Acquisitions: Evidence from IPO Firms. In Academy of Management Proceedings (Vol. 2014, No. 1, p. 14479). Academy of Management. 